\title{
Material deprivation and health: a longitudinal study
}

Anne Grete Tøge ${ }^{1,2^{*}}$ and Ruth Bell ${ }^{2}$

\begin{abstract}
Background: Does material deprivation affect the consequences of ill health? Answering this question requires that we move beyond the effects of income. Longitudinal data on material deprivation, longstanding illness and limiting longstanding illness enables investigations of the effects of material deprivation on risk of limiting longstanding illness. This study investigates whether a shift from affording to not affording a car predicts the probability of limiting longstanding ill (LLSI).

Methods: The 2008-2011 longitudinal panel of Statistics on Income, Social Inclusion and Living Conditions (EU-SILC) is utilised. Longitudinal fixed effects logit models are applied, using LLSI as dependent variable. Transition from affording a car to not affording a car is used as a proxy for material deprivation. All models are controlled for whether the person becomes longstanding ill (LSI) as well as other time-variant covariates that could affect the results.

Results: The analysis shows a statistically significant increased odds ratio of LLSI when individuals no longer can afford a car, after controlling for confounders and LSI in the previous year $(1.129, \mathrm{Cl}=1.022-1.248)$. However, when restricting the sample to observations where respondents report longstanding illness the results are no longer significant (1.032, $\mathrm{Cl}=0.910-1.171)$.

Conclusion: The results indicate an individual level effect of material deprivation on LLSI, suggesting that material resources can affect the consequences of ill health.
\end{abstract}

Keywords: Health, Longstanding illness (LSI), Limiting longstanding illness (LLSI), Social exclusion, Fixed effects

\section{Background}

Numerous studies have observed a close link between poverty and ill health [1-4], and the risk of getting a longstanding illness increases over the life course [5]. However, the extent to which illness leads to limitations in everyday life varies according to several factors, including type, stage and intensity of the health problem, personal perception of the situation, and available economic resources. Using the 2008-2011 panel of EU-SILC, this study tests the hypothesis that material deprivation among the longstanding ill leads to the experience of limitations in their activities.

\footnotetext{
* Correspondence: anne-grete.toge@hioa.no

'Department of Social Work, Child Welfare and Social Policy, Faculty of Social Sciences, Oslo and Akershus University College of Applied Sciences, P.O. box 4St. Olavs plass, NO-0130 Oslo, Norway

${ }^{2}$ Department of Epidemiology \& Public Health, Faculty of Population Health Sciences, University College London, 1-19 Torrington Place, London WC1E 7HB, Great Britain, UK
}

(c) 2016 The Author(s). Open Access This article is distributed under the terms of the Creative Commons Attribution 4.0 International License (http://creativecommons.org/licenses/by/4.0/), which permits unrestricted use, distribution, and reproduction in any medium, provided you give appropriate credit to the original author(s) and the source, provide a link to the Creative Commons license, and indicate if changes were made. The Creative Commons Public Domain Dedication waiver (http://creativecommons.org/publicdomain/zero/1.0/) applies to the data made available in this article, unless otherwise stated. 
they are in effect excluded from the ordinary living patterns, customs, and activities.

This is one of the most influential definitions of poverty and has directly influenced the definition set by the EU Council of ministers in 1985 [11, 12] and the indicators set by the EU Member States and the European Commission to monitor the development in poverty $[11,13]$. The items constituting these indicators can be grouped into three areas, i.e., self-reported economic strain; enforced lack of durables (items the household wants but cannot afford) and housing quality. While there is no clear consensus regarding the definition of material deprivation [8] - the nature of deprivation is multidimensional, where different dimensions (e.g., education, income and household types) interact [7, 14-16] - one can claim that material deprivation is closely connected to Townsend's [6] definition of poverty.

Investigating how people change as they become materially deprived or move into a materially deprived area provides an estimate closer to the true causal effects. However, peoples' self-reported indicators tend to be highly correlated over time, partly due to underlying causes such as mood on the day of interview. In order to avoid such endogeneity in longitudinal analysis, either the indicator of material deprivation or the outcome should be fairly objective measures [17]. This means that an investigation of individual changes in self-reported limitations should apply an objective measure of material deprivation, i.e., none of the measures of self-reported strain. Among the "objective" measures of households' dwelling facilities and durable, not all are good proxies of current change in material deprivation. Over a short time perspective, the material situation can change without changing the quality of the households' dwelling. The same can be argued regarding the affordability of a colour $\mathrm{TV}$, a telephone, a washing machine or a computer. After the initial purchase, one does not lose such items by experiencing increased financial difficulties, because the costs of maintaining and using these goods are low. The situation regarding car ownership is different, because the costs of keeping a car and using it are high, which means that ownership and affordability of a car is highly sensitive to financial difficulties [18]. In this study we therefore use a change from affording to not affording a car as a proxy for moving into material deprivation.

While material resources are often assumed to contribute to access to goods that help improve and maintain health, the effect of relative lack of material resources can contribute to psychosocial pathways in health. This is the notion that relative lack of material resources has psychological effects, such as sense of shame, economic worries, and anxiety about being unable to afford the customary living standards of everyday life, that trigger stress and consequent pathways to poor health [19-21]. Changes in the distribution of material resources may therefore affect population health, particularly among those in the lower end of the distribution $[4,9,10,20,22]$.

In addition to this cross-sectional understanding of outcomes as relative to other respondents/groups, it is also possible to construct a longitudinal understanding of relative, i.e., relative to the previous situation for the same individual. However, few studies have investigated such relationships longitudinally. A study using 1958 British Birth Cohort data found that risk of limiting illness at age 33 is associated with adult socioeconomic disadvantage at age 23, as well as factors including adolescent socio-emotional status, socioeconomic disadvantage in childhood, injury, and poor physical development [23]. Material deprivation indicates a long period of poverty and deprivation as it is much more strongly associated with health than income and other indicators of the socioeconomic status $[9,10]$.

The aim of this paper is to investigate whether material deprivation contributes to limitations among the longstanding ill. We investigate this question by estimating the individual change in risk of a longstanding illness becoming limiting if people can no longer afford a car.

Figure 1 illustrates the assumed relationship. Processes leading to both longstanding illness (LSI) and limitations

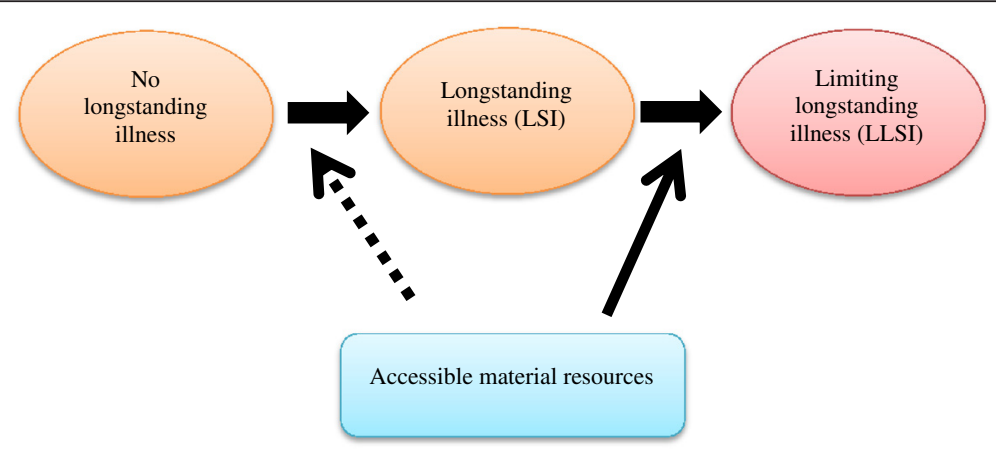

Fig. 1 Causal diagram 
in longstanding ill are affected by social determinants, i.e., the economic and social conditions that influence individual health $[24,25]$, which again affects the risk of limiting longstanding illness (LLSI) [26].

\section{Methods}

This article is based on the 2008-2011 longitudinal panel of Statistics on Income, Social Inclusion and Living Conditions (EU-SILC). EU-SILC is a four-year rotational panel, where 25 per cent of the sample is recruited and 25 per cent is dropped each year. This study utilises the balanced part of the panel, i.e., the respondents that where recruited in 2008 and followed up the next three years. This sample contains 312,556 observations among 78,139 respondents from 27 European countries. ${ }^{1}$ All variables are collected through annual harmonised target variables [27].

\section{Variables}

The aim of this paper is to investigate how individuals' risk for LLSI changes as their economic situation changes. All variables are therefore time-variant.

\section{Dependent variable}

The dependent variable is limiting longstanding illness (LLSI). This variable is obtained from an item directed to all persons who report that they have a chronic/longstanding illness or condition: "Does this illness or disability (Do any of these illnesses or disabilities) limit your activities in any way?" Yes is coded 1 and no is coded 0 . Some studies apply this item as a proxy of severe health impairments or chronic illness $[23,28,29]$. The intention of the item is to measure whether people are hampered in their usual activities by any ongoing physical or mental health problem, illness or disability [27]. Although the item is not meant to measure limitations due to financial, cultural or other none healthrelated causes, the perception of limitations is highly affected by peoples' social and economic resources and the societies' effectiveness at social inclusion. Labour market regulations and social policy affect both employers' ability to dismiss employees with chronic health conditions, and access to in kind services and financial benefits for individuals with chronic health problems. As such, LLSI is rather a measure of the consequences of ill health than illness itself. Limitations in activities imply restricted possibility to work and participate in social activities, restrictions that could lead to social isolation [30], and affect mental wellbeing [31].

\section{Explanatory variable}

The main explanatory variable is reduced access to material resources, proxied by not affording a car. Whether people can afford a car is shown to have a clear income gradient [32]. Information on affordability of a car is obtained from the item "Do you have a car?" The values are "yes", "no, cannot afford one" and "no, other reason". The variable is given the value 0 "yes" or "no, other reason", and 1 for "no cannot afford one".

\section{Covariates}

Whether the respondent has a longstanding illness (LSI) is obtained from the item "Do you have any longstanding illness, disability or infirmity. By longstanding I mean anything that has troubled you over a period of time or that is likely to affect you over a period of time?" The value "yes" is coded 1 , while "no" is coded 0 .

As change in household structure may affect the affordability of a car, all models control for partnership status (coded 1 if the person is married or cohabiting, 0 if not) and number of dependent children in the household. Age is included to control for the effect of aging on LLSI and age squared to adjust for the nonlinear shape of this effect.

\section{Statistical analysis}

Whether transition into material deprivation is associated with increased probability of LLSI is investigated using longitudinal fixed effects logit models, i.e., longitudinal models holding time-invariant factors constant. In this study the respondents' change in LLSI is a function of change in their affordability of a car. The basic model is:

$$
\begin{aligned}
\log \left(\frac{p_{i t}}{1-p_{i t}}\right)= & \mu_{i}+\beta \boldsymbol{x}_{i t}+\gamma \boldsymbol{z}_{i}+\alpha_{i} \\
& \text { for } \mathrm{t}=1, \ldots, \mathrm{T} \text { and } \mathrm{i}=1, \ldots, \mathrm{N}
\end{aligned}
$$

where $p_{i t}$ is the probability of having LLSI, $\mu_{t}$ is a timevarying intercept, $\mathbf{x}_{\mathbf{i t}}$ is the time-varying explanatory variable and confounders, $\mathbf{z}_{\mathrm{i}}$ is a vector of time-invariant predictors, and $\boldsymbol{\alpha}_{\mathrm{i}}$ denotes the combined effect of all unobserved time invariant variables [33]. Because the fixed effects model holds time-invariant factors constant and follows individuals who live in the same country for all of the observed years, cross-national differences and so called "contextual effects" will not affect the estimates unless these factors change over time [34]. Only changes in the dependent variable contribute to the estimates [33].

All statistical models are reported with and without control for time-varying covariates, i.e., partnership; number of dependent children; age and age squared. As the consequences of material deprivation may take time to manifest, final analyses apply control for a lagged transition, i.e., a transition in the previous year, into not affording a car. "Basic fixed effects models work under the assumption of strict exogeneity, which prohibits some types of feedback from past outcomes to current 
covariates and current outcome to future covariates" [35]. This possibility of reverse causation is tested by estimating individual changes in the abilities to afford a car as a function of previous changes in LSI and LLSI.

All statistical models are estimated in Stata 14, using the xtlogit command with the fixed effects model option (", fe") [33]. The main models are replicated as generalised linear mixed effect models (GLMM), which do not control for time-invariant factors at the individual and country level (reported in Table 7 in Appendix).

\section{Results}

\section{Descriptive statistics}

Table 1 shows summary statistics. Among all observations, $32.6 \%$ come from individuals reporting longstanding illness, while $25.9 \%$ come from individuals reporting their longstanding illness to be limiting. During the observational window, $9.6 \%$ of the observations are among individuals who cannot afford a car. The mean age among the respondents at the time of observation is 49.4 years, the mean number of dependent children is 0.93 , and $65.6 \%$ are married or cohabiting.

Table 2 shows yearly shares of respondents who cannot afford a car in the entire sample, in respondents with LSI and in respondents with LLSI. The share of respondents that cannot afford a car has decreased in all groups.

\section{Test for reverse causality}

The thrust of the paper is that material deprivation is associated with increased risk of LLSI, however it could be that the relationship is the other way around. If LLSI causes material deprivation rather than the other way around, than the temporal order should be higher probability of not affording a car after getting LLSI. Table 3 reports odds ratios (CI) of not affording a car as a function of changes in LLSI in the previous year. LLSI is

Table 1 Summary statistics. $N=312,556$

\begin{tabular}{lllll}
\hline Variables & $\%(\mathrm{n})$ & $\mathrm{N}$ & & \\
\hline $\begin{array}{l}\text { Dependent variable: } \\
\quad \text { Limiting longstanding } \\
\text { illness (LLSI) }\end{array}$ & $25.9(80,709)$ & 312,076 & \\
$\begin{array}{l}\text { Explanatory variable: } \\
\quad \text { Cannot afford a car }\end{array}$ & $9.6(29,805)$ & 312,076 & & \\
Covariates: & & & & \\
$\quad$ Longstanding illness (LSI) & $32.6(101,833)$ & 312,076 & & \\
$\quad$ Partnership & $65.6(204,761)$ & 312,076 & & \\
& Mean (SD) & N & Min & Max \\
Age & $49.4(17.5)$ & 312,076 & 16 & 83 \\
Age squared & $2744(1752)$ & 312,076 & 0.265 & 6.889 \\
Children & $0.93(1.31)$ & 312,076 & 0.000 & 15.000 \\
\hline
\end{tabular}

Table 2 Cannot afford a car by year in all respondents, respondents reporting LSI and respondents reporting LLI

\begin{tabular}{llllll}
\hline & \multicolumn{5}{l}{ Cannot afford a car } \\
\cline { 3 - 6 } & & 2008 & 2009 & 2010 & 2011 \\
\hline All & $\%$ & 10.0 & 9.7 & 9.4 & 9.1 \\
& $n$ & 78,019 & 78,019 & 78,019 & 78,019 \\
LSI & $\%$ & 12.1 & 11.1 & 10.7 & 10.3 \\
& $n^{a}$ & 24,382 & 24,936 & 25,800 & 26,715 \\
LLI & $\%$ & 13.2 & 12.5 & 12.5 & 11.9 \\
& $n^{a}$ & 19,056 & 19,699 & 20,254 & 21,700 \\
\hline
\end{tabular}

${ }^{a}$ Increasing because the prevalence of illness increases as people get older

significantly negatively correlated with not affording a car (Model 1a), i.e., becoming limiting longstanding ill in the previous year is associated with increased affordability of a car. The estimate is still significant when controlled for confounders (Model 1b), and becomes even stronger when controlling for changes in LSI at $t-1$ (Models 2a and 2b). A control for LSI at $t-1$ implies holding changes in LSI at previous constant, i.e., controlling whether the respondent moved into LSI in the year before the household could no longer afford a car, which could be an important confounding factor. Table 3 reveals that controlling for confounders - including LSI - a shift into LLSI one year is associated with decreased probability of not affording a car the next year. We control for transition into LSI in years before $t-1$ because EU-SILC is a four-year panel. An inclusion of LSI at $t-2$ instead of $t-1$ implies that the model only investigates the change in LLSI from 2010 to 2011. Nevertheless, when we control for this change, the results are no longer significant. Whether this is due to the short panel or the appropriate inclusion of control for "LSI at $\mathrm{t}-2$ " is not possible to determine.

\section{Results from multivariate analyses}

Table 4 reports the individual change in LLSI as a function of moving into a state where the respondent can no longer afford a car. Model 3a shows a minor, but not statistically significant, increased odds ratio of LLSI (1.045, CI =0.959-1.139) when individuals no longer can afford a car. This increased odds ratio is still not significant when controlling for confounders (1.064, CI =0.976-1.160, Model 3b). Models 4a and $4 \mathrm{~b}$ include a one year period lag of the LSI, and show a significant increased odds ratio of LLSI when individuals no longer can afford a car in both the uncontrolled (1.111, $\mathrm{CI}=1.006-1.227)$ and controlled model (1.129, $\mathrm{CI}=$ 1.022-1.248, full model is shown in Table 6 in Appendix).

\section{Sensitivity analysis}

Table 5 presents models where LSI is held constant by restricting the sample to observations where respondents 
Table 3 Cannot afford a car, as a function of previous change in LSI and LLSI. Longitudinal fixed effects logit models

\begin{tabular}{|c|c|c|c|c|}
\hline & $1 a$ & $1 b$ & $2 a$ & $2 b$ \\
\hline \multirow[t]{2}{*}{ Variables } & Cannot afford a car & Cannot afford a car & Cannot afford a car & Cannot afford a car \\
\hline & Odds ratio (95\% Cl) & Odds ratio $(95 \% \mathrm{Cl})$ & Odds ratio $(95 \% \mathrm{Cl})$ & Odds ratio $(95 \% \mathrm{Cl})$ \\
\hline \multirow[t]{2}{*}{ Limiting longstanding illness (LLSI), (t-1) } & $0.897^{* *}$ & $0.912^{*}$ & $0.868^{* *}$ & $0.881^{* *}$ \\
\hline & $(0.812-0.990)$ & $(0.825-1.008)$ & $(0.777-0.969)$ & $(0.788-0.984)$ \\
\hline \multirow[t]{2}{*}{ Longstanding illness (LSI), (t-1) } & & & 1.078 & 1.085 \\
\hline & & & $(0.965-1.205)$ & $(0.971-1.213)$ \\
\hline \multicolumn{5}{|l|}{ Covariates: } \\
\hline \multirow[t]{2}{*}{ Partnership, children, age, age squared } & No & Yes & NO & Yes \\
\hline & NO & NO & Yes & Yes \\
\hline Number of observations & 19,767 & 19,767 & 19,767 & 19,767 \\
\hline Number of respondents & 6589 & 6589 & 6589 & 6589 \\
\hline
\end{tabular}

${ }^{*}=p<0.10,{ }^{* *}=p<0.05 \&{ }^{* *}=p<0.01$

report longstanding illness (LSI). Model 5a shows a small, but not statistically significant, increased odds ratio of LLSI (1.008, CI =0.889-1.143) when individuals no longer can afford a car. This increased odds ratio is a bit steeper when controlling for confounders (1.032, CI = 0.910-1.171, Model 5b), but still not statistically significant. The direction of the results in Table 5 support the findings in Table 4, however, the correlations are weaker and not statistically significant.

\section{Discussion}

The main finding is that moving into material deprivation - measured as no longer affording a car - contributes to a restriction in everyday life among people with chronic illness. The study suggests that material deprivation restricts people from doing what they would have normally done, e.g., go to work and engage in physical and social activities. As such, this study contribute to the discussion of the causal effects of poverty on health related social exclusion. Retired and older people may be at particular risk of social isolation, and three life events are critical: retirement and losing connection with colleagues; falling ill and becoming less mobile; a spouse dying or going into care [36, 37]. Enabling particularly older people with chronic illness to participate in society might therefore mitigate both social and economic costs of ill health [38].

Albeit the current study investigates the effect of an "absolute" change from affording to not affording a car, a relative dimension is embedded in the longitudinal design; the change is relative to previous situation for the same individual. Affording a car in year $t$ will not contribute to the estimates if the person also could afford a car (or not needed it) in the previous year [ $t-1]$, it is only a change from affording to not affording a car that can explain change in LLSI. The strength of this design is that it contributes to the understanding of how life events and changing living conditions affect health and the consequences of ill health. Several studies have suggested that the composition of the local population has an effect beyond individual characteristics [34, 39, 40].

Table 4 Change in LLSI as a function of not affording a car and changes in LSI. Longitudinal fixed effects logit models

\begin{tabular}{|c|c|c|c|c|}
\hline & 3a & $3 b$ & $4 a$ & $4 b$ \\
\hline & LLSI & LLSI & LLSI & LLSI \\
\hline Variables & Odds ratio $(95 \% \mathrm{Cl})$ & Odds ratio $(95 \% \mathrm{Cl})$ & Odds ratio $(95 \% \mathrm{Cl})$ & Odds ratio $(95 \% \mathrm{Cl})$ \\
\hline \multirow[t]{2}{*}{ Cannot afford a car } & 1.045 & 1.064 & $1.111^{* *}$ & $1.129^{* *}$ \\
\hline & $(0.959-1.139)$ & $(0.976-1.160)$ & $(1.006-1.227)$ & $(1.022-1.248)$ \\
\hline \multicolumn{5}{|l|}{ Covariates: } \\
\hline Partnership, children, age, age squared & No & Yes & No & Yes \\
\hline Longstanding illness (LSI) at t & Yes & Yes & No & No \\
\hline Longstanding illness (LSI) at t-1 & No & No & Yes & Yes \\
\hline Number of observations & 93,744 & 93,744 & 55,110 & 55,110 \\
\hline Number of respondents & 23,436 & 23,436 & 18,370 & 18,370 \\
\hline
\end{tabular}

${ }^{*}=p<0.10,{ }^{* *}=p<0.05 \&{ }^{* *}=p<0.01$ 
Table 5 Change in LLSI as a function of not affording a car Longitudinal fixed effects logit models. Sample restricted to individual reporting LSI

\begin{tabular}{|c|c|c|}
\hline & $5 a$ & $5 b$ \\
\hline & LLSI & LLSI \\
\hline \multirow[t]{2}{*}{ Variables } & Odds ratio $(95 \% \mathrm{Cl})$ & Odds ratio $(95 \% \mathrm{Cl})$ \\
\hline & LLSI & LLSI \\
\hline \multirow[t]{2}{*}{ Cannot afford a car } & 1.008 & 1.032 \\
\hline & $(0.889-1.143)$ & $(0.910-1.171)$ \\
\hline \multicolumn{3}{|l|}{ Covariates: } \\
\hline $\begin{array}{l}\text { Partnership, children, age, } \\
\text { age squared }\end{array}$ & No & Yes \\
\hline Number of observations & 31,257 & 31,257 \\
\hline Number of respondents & 9559 & 9559 \\
\hline
\end{tabular}

This study adds to this knowledge by substantiating the causal pathway from material deprivation to health related social exclusion.

Nevertheless, when restricting the analysis to the longstanding ill and controlling for household structure and age, cannot afford a car is no longer a significant predictor of LLSI. This could be explained by underlying causes or social determinants that affect both material deprivation and experienced limitations [24, 25, 41]. This study could imply that such underlying factors, e.g., peoples' ability to remain their social network and relationships, could be an important factor in explaining the effect of material deprivation on LLSI.

Contextual factors e.g., accessibility and affordability of public transport, support from family, friends, local community, social capital in area of residence (extent of connectivity), and national policies to support people with LLSI) will also affect whether people need a car [42]. Investigations of contextual effects suggest that the prevalence of material deprivation, educational level and the share of lone parent households predict self-rated health at the individual level [34, 39]. Even within Norway, which is believed to be a very egalitarian country, Elstad [40] found that the broader socio-economic context affected regional mortality levels. All these studies suggest that the negative health effects of poverty diffuse into the environment in line with the prevalence of the phenomenon. Studies of contextual variation also suggest that this negative effect can be counteracted by social policy. A multilevel study of health related social exclusion among disadvantaged groups in Europe found lower risk of nonparticipation in social networks in countries with more generous provision of social security [43]. Labour market inclusion and reduced poverty among the unemployed could be particularly important. A repeated crosssectional study found higher prevalence of poverty among people with LLSI in the United Kingdom than in the more regulated Sweden and Denmark, and greater increase in poverty among people with LLSI in Sweden, that has cut back social benefits, than in Denmark and United Kingdom. The effect of moving into material deprivation may therefore be affected by several contextual factors, including social cohesion, the prevalence of disadvantages in the local area and labour market regulations and quality and generosity of social policies. The current study applies fixed effects models, separates between the reasons for not owning as "cannot afford" and "other reasons", and uses 'cannot afford a car' as a proxy for moving into material deprivation, therefore the interpretation of the estimates allows for an interpretation closer to the "real" causal effects of material deprivation. A decline in material living standards leads to elevated risk of limitations among people with chronic illness. As such, the results indicate that the current social policies cannot fully protect individuals with longstanding illness from the consequences of a decline in material living standards.

Nevertheless, "cannot afford a car" as a proxy of material deprivation cannot separate between the effects of relative deprivation and absolute poverty. No longer affording a car could imply that the family no longer prioritise having a car, in order to keep up other standards, or it could imply that their economic resources are so scarce that they could not afford a car even if they reduced other standards. As the affordability of a car only indicates the affordability of a car and not a latent construct of deprivation and living standards, there is a risk of measuring absolute material hardship rather than more complex and multidimensional aspects of poverty.

Attrition from panel studies are always problematic and can cause biased estimates [44]. EU-SILC has a rotational design, where new respondents are recruited each year and followed for up to four years. The raw panel is therefore naturally unbalanced. In the absence of a variable that assigns whether a respondent is missing because of attrition or because the last observation was the scheduled last, it is difficult to determine the impact of attrition in this study. Nevertheless, each initial sample is based on a nationally representative probability sample, where the reference population is all private households and all persons aged 16 and over. Investigations of attrition in the European Community Household Panel (ECHP), which was the precursor to EU-SILC found that moving and change of interviewer were the most prominent predictors of attrition [45].

Albeit longitudinal analysis can establish a temporal correlation, the challenge of detecting the causal direction of the relationship remains [35]. There is limited evidence for a reverse causality, i.e., LLSI causing a move from affording to not affording a car. The evidence for a causal effect of material deprivation on 
LLSI would be strengthened if the study could establish the temporal order; if a person gets ill health $[t]$, remains ill and cannot afford a car $[t+1]$, and then becomes limiting longstanding ill $[t+2]$. However, the EU-SILC panel is too short to provide statistical power for such an investigation.

\section{Conclusion}

The results indicate an individual level effect of material deprivation on LLSI, and thereby illustrates the importance of material resources in keeping people with LSI free of limitations for as long as possible. This study does not provide any evidence for possible effective prevention, however, it suggests that further research should investigate effects of policies and schemes aimed at reducing the negative health effects of poverty and material deprivation.

\section{Endnotes}

${ }^{1}$ Romania, Hungary, Sweden, Bulgaria, Finland, Austria, Italy, Latvia, Portugal, Cyprus, Czech Republic, Norway, Malta, Slovenia, Netherlands, Slovakia, France, Lithuania, Greece, Luxembourg, Poland, Spain, Belgium, Denmark, Estonia, Iceland and United Kingdom. Croatia joined in 2009, and are therefore not included.

\section{Appendix}

Table 6 Change in LLSI as a function of not affording a car and changes in LSI. Longitudinal fixed effects logit models

\begin{tabular}{ll} 
& $4 \mathrm{~b}$ \\
Variables & LLSI \\
\hline Cannot afford a car & Odds ratio $(95 \% \mathrm{Cl})$ \\
& $1.129^{* *}$ \\
Covariates: & $(1.022-1.248)$ \\
Longstanding illness (LSI) at t-1 & $0.652^{* * *}$ \\
Partnership & $(0.622-0.683)$ \\
& 1.004 \\
Children & $(0.853-1.182)$ \\
& 0.982 \\
Age & $(0.952-1.014)$ \\
& 0.953 \\
Age squared & $(0.891-1.019)$ \\
Number of observations & $1.002^{* * *}$ \\
Number of respondents & $(1.001-1.003)$ \\
\hline
\end{tabular}

${ }^{*}=p<0.10,{ }^{* *}=p<0.05 \&{ }^{* * *}=p<0.01$
Table 7 Change in LLSI as a function of not affording a car and changes in LSI. Generalised mixed effects models

\begin{tabular}{lllll}
\hline & $3 a$ & $3 b$ & $4 a$ & $4 b$ \\
Variables & LLSI & LLSI & LLSI & LLSI \\
& $\begin{array}{l}\text { Odds ratio } \\
(95 \% \mathrm{Cl})\end{array}$ & $\begin{array}{l}\text { Odds ratio } \\
(95 \% \mathrm{Cl})\end{array}$ & $\begin{array}{l}\text { Odds ratio } \\
(95 \% \mathrm{Cl})\end{array}$ & $\begin{array}{l}\text { Odds ratio } \\
(95 \% \mathrm{Cl})\end{array}$ \\
\hline $\begin{array}{l}\text { Transition into } \\
\text { cannot afford a }^{\text {car }^{\mathrm{a}}}\end{array}$ & $1.372^{* * *}$ & $1.303^{* * *}$ & $1.428^{* * *}$ & $1.377^{* * *}$ \\
& & & &
\end{tabular}

Covariates:

Partnership,

children, age,

age squared

Longstanding Yes Nos No

illness (LSI) at $t$

Longstanding No No Yes Yes

illness (LSI) at t-1

Random-effects

$\begin{array}{llll}\text { Level 3: } & 0.180 & 0.207 & 0.116\end{array}$

Country

(1)

(14)

Level 2:

$\begin{array}{llll}(0.083-0.276) & (0.095-0.319) & (0.053-0.179) & (0.066-0.221)\end{array}$

Respondent

$\begin{array}{llll}1.300 & 1.306 & 0.928 & 0.995\end{array}$

$(1.266-1.334) \quad(1.270-1.342) \quad(0.900-0.962)$

(0.962-1.028)

Number of

312,076

312,076

234,057

234,057

observations

Number of

respondents

78,019

78,019

78,019

78,019

Number of

countries

27

27

27

27

${ }^{*}=p<0.10,{ }^{* *}=p<0.05 \&{ }^{* * *}=p<0.01$

aThe variable only includes the transition into not affording a car, not transition from not affording a car to affording a car. The variable is coded 1 the first year $[t]$ a transition from "affording a car" or "do not have a car because of other reasons" [ $t-1]$ to "no cannot afford one" [t] is observed. All observations after the transition are coded 1 in order to avoid transition back to affording a car contributing to the estimates. All other observations are coded 0

\section{Abbreviations}

$\mathrm{Cl}$, confidence intervals; EU-SILC, EU Statistics on Income, Social Inclusion and Living Conditions; LLSI, limiting longstanding illness; LSI, longstanding illness

\section{Acknowledgements}

We thank Morten Blekesaune, Kjetil van der Wel and Espen Dahl for valuable comments. However, responsibility for all conclusions drawn from the data lies entirely with the authors.

\section{Funding}

This paper was financed through Research Council of Norway, award number 221037.

\section{Availability of data and material}

Eurostat grants access to EU-SILC microdata for scientific purposes only. To apply for access, the organisation must first be recognised by Eurostat as a research entity-a university, research institution or research department. Once Eurostat has recognised the organisation as a research entity, one can apply for access by submitting a research proposal. Detailed information on the application process can be found here: http://ec.europa.eu/eurostat/documents/203647/771732/How_to_apply_for_microdata_access.pdf. 


\section{Authors' contributions}

AGT carried out the statistical analyses and wrote the first draft for the manuscript. RB developed the draft, contributed to the interpretation of the results and improved the discussion. Both authors read and approved the final manuscript.

\section{Competing interests}

The authors declare that they have no competing interests.

\section{Consent for publication}

Not applicable.

\section{Ethics approval and consent to participate}

Access to the EU-SILC microdata is provided by Eurostat (research project reference number 58/2013-EU-SILC). EU-SILC microdata operate under a framework Regulation of the Council and the Parliament (Regulation (EC) No 1177/2003) and a series of Commission implementing Regulations. The microdata do not contain any administrative information such as names or addresses that would allow direct identification.

\section{Received: 17 December 2015 Accepted: 20 July 2016}

Published online: 08 August 2016

\section{References}

1. Hahn RA, Eaker ED, Barker ND, Teutsch SM, Sosniak WA, Krieger N. Poverty and death in the United States. Int J Health Serv. 1996;26(4):673-90.

2. Dowler E, Dobson B. Nutrition and poverty in Europe: an overview. Proc Nutr Soc. 1997;56(1A):51-62.

3. Santana P. Poverty, social exclusion and health in Portugal. Soc Sci Med. 2002;55(1):33-45.

4. Pförtner T-K, Elgar FJ. Widening inequalities in self-rated health by material deprivation? A trend analysis between 2001 and 2011 in Germany. J Epidemiol Community Health. 2016;70(1):82-9.

5. Ben-Shlomo Y, Kuh D. A life course approach to chronic disease epidemiology: conceptual models, empirical challenges and interdisciplinary perspectives. Int J Epidemiol. 2002:31(2):285-93.

6. Townsend P. Poverty in the United Kingdom : a survey of household resources and standards of living. Harmondsworth: Penguin; 1979

7. Saunders P, Adelman L. Income poverty, deprivation and exclusion: a comparative study of Australia and Britain. J Soc Policy. 2006;35(04):559-84.

8. Beverly S. Measures of material hardship: rationale and recommendations. J Poverty. 2001;5(1):23-41.

9. Pförtner T-K, Andress $\mathrm{H}-\mathrm{J}$, Janssen $\mathrm{C}$. Income or living standard and health in Germany: different ways of measurement of relative poverty with regard to self-rated health. Int J Public Health. 2011;56(4):373-84.

10. Gunasekara Fl, Carter KN, Crampton P, Blakely T. Income and individual deprivation as predictors of health over time. Int J Public Health. 2013;58(4): 501-11

11. Fusco A, Guio A-C, Marlier E. Building a material deprivation index in a multinational context: lessons from the EU experience. In: Berenger $\mathrm{V}$, Bresson F, editors. Poverty and social exclusion around the mediterranean sea, vol. 9. US: Springer; 2013. p. 43-71.

12. Lister R. Poverty. Cambridge: Polity; 2004.

13. Guio A-C, Gordon D, Marlier E. Measuring material deprivation in the EU: indicators for the whole population and child-specific indicators - 2012 edition. In: Methodologies \& working papers. Luxembourg: European Union; 2012.

14. Whelan CT, Lucchini M, Pisati M, Maître B. Understanding the socioeconomic distribution of multiple deprivation: an application of selforganising maps. Res Soc Stratification Mobility. 2010;28(3):325-42.

15. Bak CK, Larsen JE. Social exclusion or poverty individualisation? An empirical test of two recent and competing poverty theories. Eur J Soc Work. 2015; 18(1):17-35.

16. Whelan CT, Nolan B, Maître B. Multidimensional poverty measurement in Europe: an application of the adjusted headcount approach. J Eur Soc Policy. 2014;24(2):183-97.

17. Manski CF. Identification of endogenous social effects: the reflection problem. Rev Econ Stud. 1993;60(3):531-42.

18. Halleröd B. Deprivation and poverty: a comparative analysis of Sweden and Great Britain. Acta Sociologica. 1996;39(2):141-68.
19. Kearns A, Whitley E, Bond L, Egan M, Tannahill C. The psychosocial pathway to mental well-being at the local level: investigating the effects of perceived relative position in a deprived area context. J Epidemiol Community Health. 2013:67(1):87-94.

20. Wilkinson RG, Pickett K. The spirit level: why more equal societies almost always do better. London: Allen Lane; 2011.

21. Zimmerman FJ, Bell JF. Income inequality and physical and mental health: testing associations consistent with proposed causal pathways. J Epidemiol Community Health. 2006;60(6):513-21.

22. Wilkinson RG. Socioeconomic determinants of health: health inequalities: relative or absolute material standards? BMJ. 1997:314(7080):591.

23. Power C, Li L, Manor O. A prospective study of limiting longstanding illness in early adulthood. Int J Epidemiol. 2000;29(1):131-9.

24. Marmot M. The status syndrome: how social standing affects our health and longevity. New York: Times Books; 2004.

25. Marmot M, Wilkinson R (Eds.). Social determinants of health. New York: Oxford University Press; 2005

26. Manor O, Matthews S, Power C. Self-rated health and limiting longstanding illness: inter-relationships with morbidity in early adulthood. Int J Epidemiol. 2001;30(3):600-7.

27. Eurostat. Description of target variables: cross-sectional and longitudinal 2011 operation (Version May 2011). Eurostat; 2011. https:/circabc.europa.eu/ sd/a/1ad4dc02-7695-4765-b6db-c609acb1a162/SILC065\%20operation\% 202011\%20VERSION\%20MAY\%202011.pdf

28. Falk J, Bruce D, Burström B, Thielen K, Whitehead M, Nylén L. Trends in poverty risks among people with and without limiting-longstanding illness by employment status in Sweden, Denmark, and the United Kingdom during the current economic recession-a comparative study. BMC Public Health. 2013;13(1):925

29. Lindholm C, Burström B, Diderichsen F. Does chronic illness cause adverse social and economic consequences among Swedes? Scand J Public Health. 2001;29(1):63-70.

30. Marcus G, Neumark T, Broome S. Power lines. In: RSA projects. 2011.

31. Cable N, Bartley M, Chandola T, Sacker A. Friends are equally important to men and women, but family matters more for men's well-being. J Epidemiol Community Health. 2013;67(2):166-71.

32. McKnight A. Measuring material deprivation over the economic crisis: does a re-evaluation of 'need' affect measures of material deprivation? In: GINI policy paper, vol. 4. 2013

33. Allison PD. Fixed effects regression models. Los Angeles: Sage Thousand Oaks; 2009.

34. Grisotto L, Catelan D, Accetta G, Biggeri A. Material deprivation as marker of health needs. Statistica. 2010;70(3):343-52.

35. Gunasekara Fl, Richardson K, Carter K, Blakely T. Fixed effects analysis of repeated measures data. Int J Epidemiol. 2014;43(1):264-69.

36. Hollis J, Lichstenstein E, Vogt T, Stevens V, Biglan A. Nurse-assisted counseling for smokers in primary care. Ann Intern Med. 1993;118:521-5.

37. Wilson DM, Harris A, Hollis V, Mohankumar D. Upstream thinking and health promotion planning for older adults at risk of social isolation. Int J Older People Nurs. 2011:6(4):282-8.

38. Marmot M, Allen J, Bell R, Bloomer E, Goldblatt P. WHO European review of social determinants of health and the health divide. Lancet. 2012;380(9846):1011-29.

39. Godley J, Haines VA, Hawe P, Shiell A. Small area contextual effects on selfreported health: evidence from Riverside, Calgary. BMC Public Health. 2010; 10(1):264

40. Elstad Jl. Does the socioeconomic context explain both mortality and income inequality? Prospective register-based study of Norwegian regions. Int J Equity Health. 2011;10(1):7.

41. Marmot M, Bloomer $E$, Goldblatt $P$. The role of social determinants in tackling health objectives in a context of economic crisis. Public Health Rev. 2013:35(1):1-24

42. Church A, Frost M, Sullivan K. Transport and social exclusion in London. Transp Policy. 2000;7(3):195-205.

43. Saltkjel T, Dahl E, van der Wel KA. Health related social exclusion in Europe: a multilevel study of the role of welfare generosity. Int J Equity Health. 2013;12(1):81.

44. Alderman H, Behrman JR, Kohler H-P, Maluccio JA, Watkins SC. Attrition in longitudinal household survey data. Demogr Res. 2001;5(4):79-124.

45. Behr A, Bellgardt $\mathrm{E}$, Rendtel U. Extent and determinants of panel attrition in the European Community Household Panel. Eur Sociol Rev. 2005;21 (5):489-512. 